\title{
Selection methods in healthcare professions: where are we now and where next?
}

\author{
Fiona Patterson $^{1,2}$ (D) $\cdot$ Jennifer Cleland $^{3} \cdot$ Fran Cousans $^{1,4}$
}

Received: 22 December 2016/ Accepted: 2 January 2017/Published online: 27 March 2017

(C) Springer Science+Business Media Dordrecht 2017

\section{Introduction}

This special issue is intended to provide a platform to present state-of-the-art research on key issues in selection and increasing diversity in medicine, and to promote further debate between colleagues across the globe. Selection into medicine continues to be highly competitive and so can be highly resource intensive, creating a practical issue for recruiters. Depending on the method and procedures used for selection, a major risk of litigation exists if these are viewed as 'unfair' by key stakeholders. Political considerations also influence selection practices (Anderson 2011; Patterson et al. 2012), such as an increased emphasis on widening access and promoting diversity. Selection is therefore 'high-stakes' from many perspectives and policy should be heavily influenced by good quality research evidence.

Although selection systems differ internationally, prior academic attainment is traditionally the primary basis for selection into medical school, and is usually assessed at an initial screening stage. Typically, academic indicators are used as the basis for initial shortlisting decisions in combination with personal statements, references, aptitude tests or a combination of all three, usually followed by an interview as the final stage of a selection process. However, there are several concerns regarding this approach. Research has concluded that academic performance is a good, but not perfect, predictor of performance, accounting for approximately $23 \%$ of the variance in performance in undergraduate

Fiona Patterson

f.patterson@workpsychologygroup.com

1 Work Psychology Group, 27 Brunel Parkway, Pride Park, Derby DE24 8HR, UK

2 Department of Psychology, University of Cambridge, Downing Street, Cambridge CB2 3EB, UK

3 Institute of Education for Medical and Dental Sciences, School of Medicine, University of Aberdeen, Aberdeen, UK

4 University of Leicester, Leicester, UK 
medical training and 6\% in postgraduate performance (Trost et al. 1998). Emerging research clearly demonstrates that academic ability is a necessary but not sufficient condition to ensure a trainee becomes a competent clinician (Patterson et al. 2016a). Thus, although academic ability is a good predictor of performance early in the curriculum, it is much less predictive when trainees enter clinical practice, when other attributes become increasingly important in predicting performance.

In addition to academic ability, it is vital that medical students also possess a range of other important skills and qualities (Ferguson et al. 2014). There is increasing recognition that there is more to being a capable medical student or doctor than academic performance. In other words, medical schools must select applicants who will not only excel academically but who also possess personality traits and values befitting a career in medicine such as compassion and inter-personal skills. This follows a deeper analysis of the so-called (and somewhat artificial) divide in criteria between the academic/cognitive (e.g. clinical knowledge) and the non-academic (e.g. empathy, communication, integrity). Conceptually, a key issue is whether medical schools should aim to select individuals who will make successful students or those who will make competent clinicians (Patterson and Ferguson 2010)_or whether is it possible to select equally on both academic and non-academic capacities. This debate links back to widening access and increasing diversity in that relative attainment is strongly linked to inequalities in schooling, broadening medical selection to incorporate non-academic qualities may compensate in some way for deep rooted societal issues which are beyond the reach of those selecting into medicine to influence to any great extent (Nicholson and Cleland 2015).

In examining these issues, the collection of papers and commentaries presented are grouped into three broad themes to guide readers, including; (1) selecting for important personal (non-academic) attributes, (2) examining the validity and quality of different selection methods, and (3) widening access and promoting diversity in selection. Inevitably, as highlighted above, there are links and parallels between each theme. They reflect areas of current priorities for healthcare researchers and practitioners alike, particularly within a global climate that increasingly requires healthcare educators to diversify their workforce while also doing 'more with less', in vocations that are already highly challenging (Mealer et al. 2012; Dhingra et al. 2016; Lindwall et al. 2014). In this paper, we draw together some key messages from the research presented and explore an agenda for future research.

\section{How can we best select for important personal attributes and values?}

Research in this area is expanding rapidly and there is an increasing recognition that personal attributes such as empathy, integrity, resilience and teamwork are a crucial consideration in the selection of healthcare professionals (e.g. SEEG 2014; McLachlan 2010; Stratton and Elam 2014; Patterson et al. 2015). Nonetheless, knowledge and evidence-based practice regarding selection of such attributes is undeniably in its embryonic stages in comparison to cognitive and academic assessments, which has over 100 years of research evidence behind it (e.g. McKeen Cattell 1906; Smyth 1946; Montague and Odds 1990; Urlings-strop et al. 2013). Only in the last few decades have the professional, 'softer' skills of those working in healthcare been recognised as worthy of attention during selection processes; prior to this, selection (particularly in medicine) was based almost entirely on prior academic attainment (Cleland et al. 2012).

A challenge for researchers and practitioners alike is how best to combine assessments of academic and non-academic attributes within a single selection system, and as a result 
this is often done via (educated) guesswork, with the assumption that different selection methods will complement each other. In this issue, Cousans et al. (2016) provide preliminary evidence for the situational judgement test (SJT, non-academic) and academic performance measures used in postgraduate medical selection in the UK as being complementary in predicting subsequent in-role performance. Research suggests that SJTs may be more predictive at the lower end of a scoring distribution, and academic attainment more predictive at the higher end. This implies that non-academic attributes might be criteria to 'select out' whereas academic criteria might be used to 'select in'. While this paper adds to the scarce available literature on the impact of combining numerous methods in a selection system (Patterson et al. 2016a), there remains a critical need to examine the impact of weighting and sequencing of both non-academic and academic methods in selection system design for a range of outcomes. A recent study (Lievens et al. 2016) showed that if recruiters wished to promote widening access for less privileged students to significantly change the demography of those students selected, recruiters would need to heavily weight the non-academic assessments (i.e. an SJT) compared to more cognitivelyoriented assessments (i.e. cognitive ability tests). In practice, we are left to question whether recruiters are willing to adopt this departure in admissions policy.

A vast range of attributes and skills fall under the category of 'non-academic'. In this issue alone, professional skills (Cousans et al. 2016; Dore et al. 2016), innovation (Patterson and Zibarras 2016) and personality (Ferguson and Lievens 2016) are reported. Elsewhere, researchers have focussed on values (e.g. Patterson et al. 2015), integrity (Husbands et al. 2015) and many other non-academic attributes and skills. MacKenzie et al. (2016) paper in this special issue takes steps towards eliminating some of the attributes and traits that are not necessarily suitable to assess at the point of selection into medical school, as they are not found to be predictive of subsequent performance. The authors found these to include narcissism, aloofness, confidence, optimism, control and self-discipline among others.

Continuing to focus on the role of personality in selection for medicine, Ferguson and Lievens (2016) challenge some of the core assumptions that have typically been made in research and practice. For example, they highlight the evidence that personality traits are changeable across both the lifespan and contexts, contrary to the traditional view that personality is stable across both. The authors note that there are currently no data on how personality changes as a function of medical training, and that we need to not only know about differential prediction of personality traits across the medical career but also how this influences and is influenced by personality change. They also debate how personality assessment could allow for some assessment of contextual sensitivities or trait expression. Ferguson and Lievens (2016) similarly challenge the view of some traits being "better" than others, suggesting that selecting for a "good" trait may be too simplistic as there is a "dark side" to each. Thus, it seems that even for some of the non-academic attributes such as personality traits that have been more widely researched within and beyond the healthcare education literature, many questions remain and continue to emerge regarding how these can be best used in selection. Further, theory-driven research is required in this area to address these issues, drawing upon contemporary research in social, educational and developmental psychology.

With significant economic challenges across the globe, creative problem-solving is an attribute of increasing interest from researchers and practitioners in organisations in all sectors (Anderson et al. 2014). However, this a relatively untouched area in medicine selection, despite the pressing need for medical professionals to "do more with less", and the changing nature of many medical roles to require entrepreneurialism in the future 
(Gregory 2009). Patterson and Zibarras (2016) note that conscientiousness and innovation have been found to correlate negatively, which raises a challenging dilemma since previous research has consistently shown a positive association between conscientiousness and various indices of education and training success and job performance (McLachlan and Macnaughton 2009; Woods et al. 2016; Barrick et al. 2001). This study explores the use of a trait-based measure of creativity and innovation potential and evaluates its efficacy for use in selection for medical education; finding that different aspects of innovation are associated with different sub-facets of conscientiousness, and that motivation to change is the key significant predictor of creative problem solving, over and above personality traits. These findings prompt us to ask whether medical selection systems should move away from traditional selection processes that are aimed at fitting the person's current skill set to the role, to instead focus on potential (e.g. to innovate)?

\section{Summary}

Research suggests that consideration of less "static" approaches to measuring non-academic attributes at the time of selection (i.e. recognising that they can change) may be valuable, along with greater understanding of how, and which, measures of non-academic attributes can be integrated effectively into selection systems, and how these work in combination with other methods. A focused analysis of the extent to which certain personal attributes can be developed (or not) within education and training would inform this debate.

\section{What evidence exists regarding the validity and quality of different selection methods?}

Research presented in this issue advances the literature across a wide range of topics in this area, including analysis of the political validity (stakeholder acceptance) of the H-PAT Ireland aptitude test (Kelly and O'Flynn 2016); predictive validity of computer-based MMIs (CASPer, Dore et al. 2016); participation in extra-curricular activities (UrlingsStrop et al. 2016) and scoring methods for SJTs (De Leng et al. 2016).

Linked to considerations around widening access, many researchers are examining alternatives to 'traditional' selection methods, and initial evidence for their predictive validity is emerging. For example, in this issue Dore et al. (2016) describe a computerbased alternative to MMIs (CASPer) that can be used at the initial screening stages of an application to assess non-academic attributes and provide preliminary evidence for its predictive validity with performance on national licensure examinations. Urlings-Strop et al.'s (2016) results suggest that persistent participation in extracurricular activities of selected (compared to lottery-admitted) students favours better clinical achievement during medical school; supporting the inclusion of an individual's motivation to engage in extracurricular activities as a consideration in selection procedures. These studies explore new and innovative ways to select medical professionals of the future in ways that are viable in practice for the high volume of applicants. However, in the research more broadly, selection methods are often examined in isolation (although in reality they typically form only one part of a selection system), and longitudinal data are rarely collected which follow selected individuals throughout their training and practice to evaluate the long-term predictive validity of methods, and combinations of methods. Certainly, studies such as those presented in this issue are highly valuable, especially for methods still in their 
infancy, but the need remains for more longitudinal follow-up and a more holistic view of entire selection systems.

Considering validity and quality from a different perspective, De Leng et al. (2016) provide data which demonstrate how the scoring method applied for an SJT can impact on internal consistency reliability, adverse impact and correlations with personality dimensions. They conclude that the way of controlling for systematic error was the most influential scoring method aspect. The authors summarise that the growing international trend for the use of SJTs for selection into the medical professions must be accompanied by a thorough examination of the scoring method to be used. This is a particularly complex issue, given that SJTs are designed to be contextualised to a specific role and target different attributes, based on a job analysis (Patterson et al. 2016a), and so each SJT will have unique considerations regarding the impact of the scoring method.

Kelly and O'Flynn (2016) bring together and critically appraise evidence for the construct validity of the Health Professions Admission Test (HPAT)-Ireland, which is closely modelled on the UMAT used in Australia and New Zealand. They consider issues of stakeholder acceptance, and their narrative draws from experiences from other aptitude tests regarding early conclusions on predictive validity, susceptibility to coaching, gender, and possible socioeconomic biases.

\section{Summary}

Validity is a broad and challenging area within medical selection that poses significant questions for researchers and practitioners internationally, as demonstrated by the breadth of areas covered in this issue. One critical issue which remains is that of which outcome measures should be employed in predictive validity studies - the so-called 'criterionproblem' - as this varies notably between studies. This is partly due to the fact that there is no agreed-upon taxonomy of desirable behaviours and attitudes that indicate success as a healthcare practitioner, particularly because this is likely to differ across professions and stages of training pathways. As such, there is a need for more theoretically driven, futureoriented research aimed at identifying what a 'competent' medical worker is at the various stages of education, training and practice (see Patterson et al. 2016b for a detailed discussion).

\section{How can we best address widening access and diversity in selection?}

Both Griffin et al. (2016) and Hay et al. (2016) in this issue focus on the practice intention of 'non-traditional' students to return to their location of origin (whether areas of low socioeconomic status [SES], or rural settings, respectively). Such investigations are timely, as global calls to widen access are often driven by healthcare provision needs in underserved areas, and are underpinned by the assumption that individuals recruited into medical school from such areas will then return to practice there once qualified. However, Griffin et al.'s (2016) data do not support this assumption, finding that students from very low (and very high) SES backgrounds indicated lower intention to practice in low SES or medically underserviced areas than those from mid-range SES backgrounds. The authors propose an alternative theory: that aspiration may be driving a desire for trainee doctors to be upwardly mobile, rather than to return to areas of relative deprivation once they have moved away from them during their medical training.

Conversely, Hay et al. (2016) found that rural origin of students predicted intention to return to practice in rural settings, although not as a general practitioner (family physician) 
which is a specialty where greater numbers are needed in rural areas. As such, they conclude that rural origin widening participation initiative is only a part of the required solution to address rural health force undersupply.

Research here provides an interesting insight into the assumption that "like will return to treat like"; suggesting that this may be the case for some widening access dimensions (e.g. rural origin) but not others (e.g. SES). This, along with other research (SEEG 2014), indicates that a "one size fits all" approach is not sufficient or appropriate when addressing current and future societal healthcare needs via widening access to non-traditional students to medical school.

Longitudinal research is needed to follow up medical students admitted via widening access initiatives to ascertain whether their intentions regarding where they will practice, and in what specialty, once qualified are borne out in practice. Ajzen's Theory of Planned Behaviour would suggest that students' intentions are indeed likely to be predictive of their subsequent practice location and specialty (Ajzen and Fishbein 1980; Ajzen 1985). However, there are many intervening factors between early intention and later behaviour, including clinical experience, career and location choices of role models and peers, discovering one's own personality and skills "fit" with a particular specialty, and so on, which may affect the relationship between intention and outcome in career decision making.

Nicholson and Cleland (2016), Stringer et al. (2016) and to some extent Hay et al. (2016) in this special issue focus on widening access with the lens of "getting in" to and subsequently "getting on" in medical school (Milburn 2012). One significant concern, both from a research standpoint but also (and perhaps more significantly) from the perspective of higher education institutions, is whether encouraging and facilitating entry of nontraditional students to highly competitive healthcare degrees such as medicine, should be accompanied by ongoing support. The data presented in this special issue is somewhat conflicted on this point. Nicholson and Cleland (2016) provide a theory-driven analysis of "getting in" and "getting on" in medical school, which serves to further the literature in this area as research has been severely lacking in theoretical development to date. Their findings suggest that while widening access students were aware that "who you know", even where these ties were weak, was influential at the application and admissions stage, they seemed less aware of their need for "upwards" networking and expanding their social circles during medical school. Thus, while they do not present any outcome data, their qualitative analysis speaks to the potential for such students performing "less well" in very subtle ways once they are at medical school due to their lack of social capital. These findings highlight the need for future research to address not just how to promote diversity in selection, but also to consider a culture of inclusion once students enter education and training.

Stringer and colleagues (2016) purport that once students reach the qualifying standard for entry into medicine, socioeconomic and educational disadvantages have no apparent persistent adverse effects on educational attainment throughout medical school. On the contrary, they suggest that those students who manage to reach the qualifying standard for medical school despite the quality of the school they attended will, if anything, tend to perform better in medical school than students from high-performing schools due to their motivation and capacity to achieve “against the odds". Hay et al.'s (2016) paper also provides evidence that reducing selection cut points (academic achievement, UMAT, and interview) for rural applicants to Australian medical schools does not result in increased failure, or significantly impaired clinical performance during training. 


\section{Summary}

Widening access, promoting diversity and inclusion in the healthcare professions remains an emotive and thorny issue, with many questions still unanswered. Data presented in this issue are inconsistent regarding both where widening access students will practice once qualified, and their likelihood of successfully navigating medical school. Such discrepancies are typical of the wider research literature, and significant further investigation is required to ascertain how and if widening access works for students, higher education institutions and underserved communities, and under what conditions.

\section{Emerging issues in selection research}

Taking together the existing research and current practice, alongside the state-of-the-art research presented by authors in this issue, we propose seven key emerging issues for further consideration:

\section{Selecting for non-academic attributes requires theory-development to improve construct validity}

1. We note a considerable lack of theory-driven studies regarding which non-academic constructs are being assessed during selection, as well as the interplay between nonacademic attributes (i.e. are they necessarily mutually exclusive?). Studies examining the construct validity of methods purporting to measure non-academic attributes would therefore be timely.

2. Research that recognises the role of motivation and experience on how non-academic attributes are expressed is currently in relatively short supply. In addition, how findings from this area can be practically integrated into healthcare selection systems remains an untapped area of exploration. Studies examining the nuances of trait expression, and implications for healthcare selection systems, would therefore progress research in this area. Research here must draw upon contemporary theory regarding personality and individual differences to make advances in this field.

3. Future-focused theory development is needed to consider which non-academic attributes will be most important for healthcare professionals of the future, and how these should be selected for. As generations $\mathrm{Y}$ and $\mathrm{Z}$ enter healthcare training and practice, the role of technology in healthcare will continue to increase. As yet, there has been relatively little attention paid in the literature to what this might mean for selecting the "right" individuals to work in healthcare.

\section{Validity and quality of selection methods}

4. At present there is a paucity of longitudinal studies following healthcare students and professionals throughout their training and career. Current research often presents a picture of quantity over quality regarding selection methods in this area. As such, researchers should focus on tracking cohorts of students and trainees to collect longitudinal data regarding the predictive validity of different selection methods over time. This implies a need for increased international collaboration in selection research as too often research is based on single site studies. 
5. Data on healthcare selection methods are often reported in isolation, whereas in reality they sit within the context of wider selection systems. As such, both researchers and practitioners frequently lack the in-depth understanding required to weight and sequence methods appropriately within a selection system. Thus, research examining how selection methods can be best combined, and the subsequent impact of this on widening access priorities, is desirable.

6. As healthcare delivery becomes ever more computerised, should we prioritise technology literacy within selection systems? And what other competencies will be required of healthcare professionals in the future and near future? To answer such questions, we suggest that collaborative, inter-disciplinary research between psychologists, healthcare professionals, educationalists and technology specialists amongst others is required.

\section{Widening access, diversity and inclusion}

7. Research at present is notably sparse regarding how contextual data can be-and isused to successfully widen access to the healthcare professions. Despite much discourse regarding the importance of increasing opportunities for non-traditional students to be selected into healthcare roles, there is a dearth of evidence supporting how and which contextual data should be used to facilitate this.

Much research in the area of widening access focuses on how best to be inclusive on the basis of merit; that is, widening access is an initiative to address social justice and offer opportunities for social mobility (Gartland 2014; Jones and Thomas 2005; Bowl and Hughes 2013; Sheeran et al. 2007; Nicholson and Cleland 2015). However, there is an opportunity to view the selection of healthcare professionals in a more complete way, and to assign a different meaning to diversity. In other words, what a 'competent' healthcare professional looks like may differ depending on specialty, and place of work, and so selecting for a range of knowledge, skills and attributes may be desirable. $R e$ search exploring how we can diversify healthcare selection in this way should be prioritised.

\section{Key topics for future research}

In addressing some of these emerging issues, we propose eight key topics as priorities for future research (acknowledging that this list is not exhaustive).

\section{Future-oriented job analysis studies are required to inform future selection criteria}

Best practice selection involves a thorough job analysis and the use of evidence from validation studies to continually improve accuracy and fairness in developing selection criteria. A key question is what attributes are important to be an effective clinician in the next 25 years and beyond? Use of multi-source, multi-method, future-oriented job analysis studies should be used to systematically examine this issue. 


\section{A taxonomy of the important outcome markers to judge the quality of different selection methods more accurately is required}

There is relatively little research investigating the quality of selection methods and systems in healthcare education and training other than the prediction of exam performance. Whilst these are clearly important markers in a trainee's education, they are constructed within a maximal performance assessment paradigm (i.e. the best one can do within a specified period of time), whereas less attention has been given to important markers of typical performance (how one performs day-to-day). Important personal attributes such as resilience, integrity and teamwork are rarely directly measured in licensing exams which naturally focus on clinical knowledge and clinical skills. This is especially problematic when researchers are attempting to explore the criterion-related validity of measures of non-academic attributes. That said, recent research is emerging that examines the quality of selection methods using a variety of outcome measures such as multi-source feedback, patient satisfaction and educational supervisor ratings (Naidoo et al. 2016). It is clear however, that each of these types of outcome measures have their own challenges which implies that multiple outcome criteria should be considered in future, where researchers should also consider both the convergent and discriminant validity of different selection methods.

\section{Greater focus on theoretical developments}

While empirical and methodological advancements in our understanding of selection and widening access to medicine are essential, it is also important to ensure that the field progresses theoretically. Research which focuses on advancing our understanding of existing phenomenon is required to understand better the concepts and approaches we are already using in the field. Theory can also influence the intellectual framing and dialogue about what we need to know in relation to future developments, such as the eight key topics we are suggesting as research priorities. We urge those with an interest in selection and widening access to: move the theoretical conceptualization of both the qualitative and quantitative research paradigms forward; challenge established theory to identify new lines of enquiry; and maximise the potential for theory to influence policy and practice by making clear the linkages between theory and problem-solving.

\section{A paradigm shift is required in selection system design to address widening access and diversity}

Traditional approaches to selection system design should be revisited. For example, academic indicators such as A-Levels and aptitude tests have traditionally been used as the primary screening method in healthcare education and training (McManus et al. 2013). However, emerging research suggests that it may be more appropriate to 'select out' on the basis on non-academic attributes, and subsequently 'select in' on the basis of academic indicators. For example, evidence that SJTs are most predictive towards the lower end of the distribution would support this proposal (see Cousans et al. 2016, in this issue). It may be that some academically-able individuals are fundamentally unsuited to a career in healthcare on the basis of their professional attributes and values, and as such should be removed early in the selection process. Such propositions are in line with findings from recent government enquiries in the UK (Francis 2013; Cavendish 2013) which highlighted 
major concerns about the level of compassionate care giving from healthcare professionals. Papadakis et al. (2004) finding that unprofessional behaviour in medical school is associated with subsequent disciplinary action by a state medical board in the USA also resonates here, as it does with our earlier points about the importance of longitudinal studies and appropriate outcome measures (Papadakis et al. 2004). More research is needed to examine the practical and political implications of this approach to screening candidates, and to consider alternatives to both this and the status quo.

Most (if not all) healthcare selection systems employ two or more selection methods, yet there remains a dearth of evidence regarding the optimal weightings of each stage and/ or selection method (Patterson et al. 2016a). There are many outcome criteria to consider, including widening access and the criterion problem (i.e. what do we want from a 'competent' healthcare professional?).

\section{Increased attention to explain the causes of differential attainment is required}

Although recent research has developed our understanding of widening access in relation to social (class) inequality, an adequate explanation of differential attainment regarding ethnicity continues to allude researchers; a comprehensive causal explanation for substantial differences has yet to be offered (although this phenomenon is not unique to assessment for selection; see Woolf et al. 2011). For example, Esmail and Roberts (2013) in the UK found that Black and Minority Ethnic international medical graduates were 14.7 times more likely than White UK graduates to fail the clinical skills OSCE assessment as part of the examination for Membership of the Royal College of General Practitioners. In order to address this ongoing knowledge gap, there is a need for increased research focus on the role of selection methods in promoting (or indeed prohibiting) diversity and inclusion within the healthcare professions.

\section{Studies of stakeholder acceptance and the political landscape of selection internationally}

Patterson et al. (2012) suggested that the political validity of selection system design is an important consideration. This notion refers to levels of acceptance of selection criteria and methods by a broad range of stakeholders. The reactions of applicants and recruiters are important, as are reactions from wider stakeholders, including government, regulatory bodies and the general public, which play an important role in decision-making at policy level. For example, the lottery system for medical school admissions was politically acceptable within the Netherlands for some time, but this approach was less acceptable to stakeholders elsewhere across the globe (Urlings-Strop et al. 2011). Similarly, structured interviews/MMIs are widely used medical school admissions across the globe, but are not used in Ireland due to stakeholder perceptions of fairness (Kelly et al. 2014).

Although much previous research has centred on exploring the predictive validity of selection methods, less attention has been paid to other important purposes such as; (1) a 'public relations' function (applicant experiences of an recruiter's selection procedure will influence their views of the organisation/the profession in general), (2) a function of establishing a viable psychological contract between the recruiter and those who are appointed, (3) and a function of exposing applicants to the culture of the organisation and profession (e.g. Wanous 1992). In relation to the latter, Anderson's review (2001) highlights the role of selection methods initiating a pre-entry socialization process, a concept termed 'socialisation impact'. It is proposed that selection methods commence a pre-entry 
socialisation process (Feldman 1976; Wanous 1992) and do not merely act as neutral predictors of subsequent job performance. Rather, they unavoidably influence candidates' reactions, expectations, attitudes, career expectations and even subsequent job behaviour. Future research should explore these issues within the healthcare professions which is a high stakes, high profile selection setting for all incumbents.

\section{Use of more sophisticated methodologies and psychometric indicators for assessing the quality of selection methods and systems}

In evaluating licensure exams, the reliability of the assessments is viewed as the 'gold standard'; to ensure a trainee is safe for subsequent independent practice. In selection, the predictive validity of the assessments is the gold standard, as students and trainees enter supervised education, and recruiters wish to appoint those most likely to succeed in training. Selection research in healthcare has tended to focus largely on reliability (e.g. how many stations are required for an MMI to be reliable), here we remind readers that it is quite possible to be reliably wrong (Patterson and Ferguson 2012), and greater attention should be paid to establishing the predictive and construct validity of selection systems.

Establishing the validity of a selection system however presents many methodological, conceptual and practical problems, including range restriction, attrition, bias in outcome data and ethical considerations to name a few. As such, the process of assessing the validity of selection methods is complex and can (and in many cases should) take several years. Due to the inherent complexities of validation, piloting is essential to ensure that research designs are robust and practicable. As a result, assessing the quality of selection methods and systems is an expensive process, and can often be over-simplified which reduces how informative and applicable data collected can be. More high quality, large-scale, international, longitudinal research which takes account of the many variables impacting on the quality of selection methods and systems is required to gain a more sophisticated understanding of these issues in future.

\section{How do we best use information at selection to inform early education and training interventions?}

As selection is the first assessment in the education pathway, where resources allow, information gathered at the point of selection should be used to shape and potentially accelerate subsequent training and educational interventions. For example, if a trainee is borderline in some attributes, they may be enrolled in an education programme to help them develop these attributes and related skills required in the role they have applied for, where early education interventions could significantly accelerate learning and development. Research is also required to ascertain student reactions to such interventions and guidance for how this could work in practice.

In conclusion, although historically research into selection for healthcare education and practice has painted a picture of quantity over quality, this landscape is changing rapidly, and some key insights are now emerging to guide further enquiry and to influence future policy and practice internationally. This special issue is intended as a platform for future research and promote further debate between colleagues across the globe on these issues. 


\section{References}

Ajzen, I. (1985). From intentions to actions: A theory of planned behavior. In J. Kuhl \& J. Beckman (Eds.), Action-control: From cognition to behavior (pp. 11-39). Heidelberg: Springer.

Ajzen, I., \& Fishbein, M. (1980). Understanding attitudes and predicting social behavior. Englewood Cliffs, NJ: Prentice-Hall.

Anderson, N. R. (2001). Towards a theory of socialization impact: Selection as pre-entry socialization. International Journal of Selection and Assessment, 9(1-2), 84-91.

Anderson, N. (2011). Perceived Job Discrimination: Toward a model of applicant propensity to case initiation in selection. International Journal of Selection and Assessment, 19(3), 229-244. doi:10.1111/ j.1468-2389.2011.00551.x.

Anderson, N. R., Potocnik, K., \& Zhou, J. (2014). Innovation and creativity in organizations: A state-of-thescience review, prospective commentary, and guiding framework. Journal of Management, 40(5), 1297-1333. http://jom.sagepub.com/content/40/5/1297.short. Accessed 10 July 2014.

Barrick, M. R., Mount, M. K., \& Judge, T. A. (2001). Personality and performance at the beginning of the new millennium: What do we know and where do we go next? International Journal of Selection and Assessment, 9(1 and 2), 9-30.

Bowl, M., \& Hughes, J. (2013). Discourses of "Fair Access" in English higher education. Widening particip lifelong learn. Widening Participation and Lifelong Learning, 15(4), 7-25.

Cavendish, C. (2013). The Cavendish review: An independent review into healthcare assistants and support workers in the NHS and social care settings. https://www.gov.uk/government/uploads/system/uploads/ attachment_data/file/236212/Cavendish_Review.pdf. Accessed 17 Apr 2015.

Cleland, J., Dowell, J., McLachlan, J., Nicholson, S., \& Patterson, F. (2012). Identifying best practice in the selection of medical students (literature review and interview survey). http://www.gmc-uk.org/ Identifying_best_practice_in_the_selection_of_medical_students.pdf_51119804.pdf.

Cousans, F., Patterson, F., Edwards, H., Walker, K., McLachlan, J., \& Good, D. (2016). Evaluating the complementary roles of an SJT and academic assessment for entry into clinical practice. Advances in Health Sciences Education. doi:10.17863/CAM.4578.

De Leng, W. E., Stegers-Jager, K. M., Husbands, A., Dowell, J. S., Born, M. Ph., \& Themmen, A. P. N. (2016). Scoring method of a situational judgment test: Influence on internal consistency reliability, adverse impact and correlation with personality? Advances in Health Sciences Education, 1-23. doi:10. 1007/s10459-016-9720-7.

Dhingra, M., Tewari, R., \& Li, M. (2016). Resilience training in medical school: The solution to doctor burnout? Medical teacher, 38(3), 319-20. http://www.ncbi.nlm.nih.gov/pubmed/26558496. Accessed 8 Aug 2016.

Dore, K. L., Reiter, H. I., Kreuger, S., \& Norman, G. R. (2016). CASPer, an online pre-interview screen for personal/professional characteristics: Prediction of national licensure scores. Advances in Health Sciences Education, 1-10. doi:10.1007/s10459-016-9739-9.

Esmail, A., \& Roberts, C. (2013). Academic performance of ethnic minority candidates and discrimination in the MRCGP examinations between 2010 and 2012: Analysis of data. BMJ, 347, f5662.

Feldman, D. C. (1976). A contingency theory of socialization. Administrative Science Quarterly, 21, 433-452.

Ferguson, E., \& Lievens, F. (2016). Future directions in personality, occupational and medical selection: Myths, misunderstandings, measurement, and suggestions. Advances in Health Sciences Education. doi:10.1007/s10459-016-9751-0.

Ferguson, E., Semper, H., Yates, J., Fitzgerald, E., Skatova, A., \& James, D. (2014). The "dark side" and "bright side" of personality: When too much conscientiousness and too little anxiety are detrimental with respect to the acquisition of medical knowledge and skill. PLOS ONE, 9(2), e88606.

Francis, Q. C., \& Francis, Q. (2013). Report of the mid staffordshire NHS foundation trust public inquiry. http://www.midstaffspublicinquiry.com/sites/default/files/report/Executivesummary.pdf. Accessed 17 Apr 2015.

Gartland, C. (2014). STEM strategies: Student ambassadors and equality in higher education (1st ed.). London: Institute of Education Press, University of London.

Gregory, S. (2009). General practice in England: An overview. http://www.kingsfund.org.uk/sites/files/kf/ general-practice-in-england-overview-sarah-gregory-kings-fund-september-2009.pdf.

Griffin, B., Porfeli, E., \& Hu, W. (2016). Who do you think you are? Medical student socioeconomic status and intention to work in underserved areas. Advances in Health Sciences Education, 1-14. doi:10. 1007/s10459-016-9726-1.

Hay, M., Mercer, A., Lichtwark, I., Tran, S,. Hodgson, W. C., Aretz, H. T., \& Gorman, N. (2016). Selecting for a sustainable workforce to meet the future healthcare needs of rural communities in Australia. Advances in Health Sciences Education, 1-19. doi:10.1007/s10459-016-9727-0. 
Husbands, A., Rodgerson, M., Dowell, J., \& Patterson, F. (2015). Evaluating the validity of an integritybased situational judgement test for medical school admissions. BMC Medical Education, 15(1), 144. http://www.biomedcentral.com/1472-6920/15/144. Accessed 8 Aug 2016.

Jones, R., \& Thomas, L. (2005). The 2003 UK government higher education white paper: A critical assessment of its implications for the access and widening participation agenda. Journal of Education Policy, 20(5), 615-630.

Kelly, M. E., Gallagher, N., Dunne, F., \& Murphy, A. (2014). Views of doctors of varying disciplines on HPATIreland as a selection tool for medicine. Medical Teacher, 36(9), 775-782.

Kelly, M. E., \& O'Flynn, S. (2016). The construct validity of HPAT-Ireland for the selection of medical students: Unresolved issues and future research implications. Advances in Health Sciences Education, 1-20. doi:10.1007/s10459-016-9728-Z.

Lievens, F., Patterson, F., Corstjens, J., Martin, S., \& Nicholson, S. (2016). Widening access in selection using situational judgement tests: Evidence from UKCAT. Medical Education, 50(6), 624-636.

Lindwall, M., Gerber, M., Jonsdottir, I. H., Borjesson, M., \& Ahlborg, G., Jr. (2014). The relationships of change in physical activity with change in depression, anxiety, and burnout: A longitudinal study of swedish healthcare workers. American Psychological Association, 33(11), 1309-1318.

MacKenzie, R. K., Dowell, J., Ayansina, D., \& Cleland J. A. (2016). Do personality traits assessed on medical school admission predict exit performance? A UK-wide longitudinal cohort study. Advances in Health Sciences Education, 1-21. doi:10.1007/s10459-016-9715-4.

McKeen Cattell, J. (1906). A statistical study of american men of science: The selection of a group of one thousand scientific men on JSTOR. Science, 24(621), 658-665. http://www.jstor.org/stable/1632227? seq=2\#page_scan_tab_contents.

McLachlan, J. (2010). Measuring conscientiousness and professionalism in undergraduate medical students. The Clinical Teacher, 7(1), 37-40. http://www.ncbi.nlm.nih.gov/pubmed/21134141. Accessed 7 Jan 2016.

McLachlan, J. C., \& Macnaughton, J. (2009). The conscientiousness index: A novel tool to explore students' professionalism. Academic Medicine, 84(5), 559-565.

McManus, I. C., Dewberry, C., Nicholson, S., Dowell, J., Woolf, K., \& Potts, H. (2013). Construct-level predictive validity of educational attainment and intellectual aptitude tests in medical student selection: Meta-regression of six UK longitudinal studies. BMC Medicine, 11, 243. http://www.pubmedcentral. nih.gov/articlerender.fcgi?artid=3827328\&tool=pmcentrez\&rendertype $=$ abstract.

Mealer, M., Jones, J., Newman, J., McFann, K., Rothbaum, B., \& Moss, M. (2012). The presence of resilience is associated with a healthier psychological profile in intensive care unit (ICU) nurses: Results of a national survey. International Journal of Nursing Studies, 49(3), 292-299. http://www. ncbi.nlm.nih.gov/pubmed/21974793. Accessed 8 Aug 2016.

Milburn, A. (2012). University challenge: How higher education can advance social mobility. Education empirical research database, pp. 1-94. https:/www.gov.uk/government/uploads/system/uploads/ attachment_data/file/80188/Higher-Education.pdf. Accessed 20 Apr 2015.

Montague, W., \& Odds, F. C. (1990). Academic selection criteria and subsequent performance. Medical Education, 24(2), 151-157. http://doi.wiley.com/10.1111/j.1365-2923.1990.tb02514.x. Accessed 8 Aug 2016.

Naidoo, S., Lopes, S., Patterson, F., Mead, H., \& MacLeod, S. (2016). Can colleagues', patients' and supervisors' assessments predict successful completion of postgraduate medical training? Medical Education, 1-9. doi:10.1111/medu.13128.

Nicholson, S., \& Cleland, J. A. (2015). Reframing research on widening participation in medical education. In Researching medical education. Oxford: Wiley-Blackwell, pp. 231-242.

Nicholson, S., \& Cleland, J. A. (2016). "It's making contacts": Notions of social capital and implications for widening access to medical education. Advances in Health Sciences Education, 1-14. doi:10.1007/ s10459-016-9735-0.

Papadakis, M., Hodgson, C. S., Teherani, A., \& Kohatsu, N. D. (2004). Unprofessional behavior in medical school is associated with subsequent disciplinary action by a State Medical Board. Academic Medicine, 79(3), 244-249. http://content.wkhealth.com/linkback/openurl?sid=WKPTLP:landingpage \&an=00001 888-200403000-00011\%5Cnhttp://www.ncbi.nlm.nih.gov/pubmed/14985199.

Patterson, F., \& Ferguson, E. (2010). Selection for medical education and training. In T. Swanick (Ed.), Understanding medical education: Evidence, theory and practice (pp. 352-365). Oxford: Wiley.

Patterson, F., \& Ferguson, E. (2012). Testing non-cognitive attributes in selection centres: How to avoid being reliably wrong. Medical Education, 46(3), 240-242.

Patterson, F., Knight, A., Dowell, J., Nicholson, S., Cousans, F., \& Cleland, J. (2016a). How effective are selection methods in medical education and training? Evidence from a systematic review. Medical Education, 50, 36-60. 
Patterson, F., Lievens, F., Kerrin, M., Zibarras, L., \& Carette, B. (2012). Designing selection systems for medicine: The importance of balancing predictive and political validity in high-stakes selection contexts. International Journal of Selection and Assessment, 20(4), 486-496.

Patterson, F., Prescott-Clements, L., Zibarras, L., Edwards, H., Kerrin, M., \& Cousans, F. (2015). Recruiting for values in healthcare: A preliminary review of the evidence. Advances in Health Sciences Education. http://link.springer.com/10.1007/s10459-014-9579-4.

Patterson, F., \& Zibarras, L. D. (2016). Selecting for creativity and innovation potential: Implications for practice in healthcare education. Advances in Health Sciences Education, 1-12. doi:10.1007/s10459016-9731-4

Patterson, F., Zibarras, L., \& Ashworth, V. (2016b). Situational judgement tests in medical education and training: Research, theory and practice-AMEE guide no. 100. Medical Teacher (in press).

SEEG. (2014). Selecting for excellence final report. http://www.medschools.ac.uk/SiteCollection Documents/Selecting-for-Excellence-Final-Report.pdf.

Sheeran, Y., Brown, B. J., \& Baker, S. (2007). Conflicting philosophies of inclusion: The contestation of knowledge in widening participation. London Review of Education, 5(3), 249-263.

Smyth, D. H. (1946). Some principles in selection of medical students. British Medical Journal, 2(4471), 357.

Stratton, T. D., \& Elam, C. L. (2014). A holistic review of the medical school admission process: Examining correlates of academic underperformance. Medical Education Online, 19(1), 1-7.

Stringer, N., Chan, M., Bimpeh, Y., \& Chan, P. (2016). Preadmission schooling context helps to predict examination performance throughout medical school. Advances in Health Sciences Education, 1-15. doi:10.1007/s10459-016-9714-5.

Trost, G., Nauels, H., \& Klieme, E. (1998). The relationship between different criteria for admission to medical school and student success. Assessment in Education, 5(2), 247-254.

Urlings-Strop, L. C., Stegers-Jager, K. M., Stijnen, T., \& Themmen, A. (2013). Academic and non-academic selection criteria in predicting medical school performance. Medical Teacher, 35(6), 497-502. doi:10. 3109/0142159X.2013.774333.

Urlings-Strop, L. C., Themmen, A. P. N., \& Stegers-Jager, K. M. (2016). The relationship between extracurricular activities assessed during selection and during medical school and performance. Advances in Health Sciences Education, 1-12. doi:10.1007/s10459-016-9729-y.

Urlings-Strop, L. C., Themmen, A. P., Stijnen, T., \& Splinter, T. A. (2011). Selected medical students achieve better than lottery-admitted students during clerkships. Medical Education, 45(10), 1032-1040.

Wanous, J. P. (1992). Organizational entry: Recruitment, selection, orientation, and socialization of newcomers. London: Prentice Hall.

Woods, S. A., Patterson, F., Koczwara, A., \& Sofat, J. (2016). The value of being a conscientious learner: Examining the effects of the big five personality traits on self-reported learning from training. Journal of Workplace Learning, 28(7), 424-434.

Woolf, K., Potts, H. W. W., \& McManus, I. C. (2011) Ethnicity and academic performance in UK trained doctors and medical students: Systematic review and meta-analysis. BMJ, 342(mar08 1), d901-d901. 